\title{
Improving ESL Learners' Comprehension through Motivational Synergy
}

\author{
* Marya Sarwar, Lecturer \\ ** Dr. Rubina Masum, Assistant Professor \\ *** Sadia Gondal, Assistant Professor (Corresponding Author)
}

\begin{abstract}

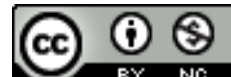

The present study focuses on the use of Motivational Synergy as means to ameliorate the comprehension of ESL Learners at various campuses of the University of Education. The study is correlational. The survey method was adopted to carry out the research. A convenient purposive sampling technique was used to collect the sample which is comprised of 100 public sector university students including 33\% males and 67\% females studying in the M.A. English program. This study focused on reading comprehension and listening comprehension. The results show that bottom-up training had a negative impact on comprehension. In contrast, top-down training positively affected fluency but had no impact on comprehension. Further, the results do suggest that fast-paced reading may potentially lead to improved comprehension. These findings have implications for the type of language instruction used in classrooms and, therefore, for teachers of adult ESL learners.

Keywords: Reading Fluency; Comprehension; Isolated Word Training; Bottom-Up Strategy; TopDown Strategy

\section{Introduction}

English is a global and international language. One needs to be skillful in the English language if one needs to become part of global, academic, professional, and regional communities. Non-English speaking countries consider English as a foreign language and they are considered as second language learners as they struggle to develop proficiency in this language (Tapinta, P. 2006). Duke and Carlisle (2011) define comprehension as a method or an activity of constructing or creating meaning through oral and written language. Pourhesin (2012) asserts that certain factors affect the pronunciation of the English language. These factors are listed as attitude, motivation, and exposure to better speaking.

Vandergrift (2007) proposes that acquiring L2 listening is important to understand the target language and to take advantage of various aural and visual L2 which can have access through online audios, videos, YouTube, and blogs. Cummins (2000) states that high cognitively developed skills are required to achieve an advanced level of performance at the academic level in second language learning. Learners need to have general communicative proficiency to learn content instruction through the language.

Motivation is usually considered to be an urge that moves someone to a certain action or specific plan. The term in itself is not simple to define but this phenomenon is not only used in everyday life but also many fields and studies of social sciences, for example in different fields of psychology, educational studies and in the field of applied linguistics (Gardener \& Lambert, 1972). Motivation is a driving force that directs a person to initiate and continue activity to follow his pursuit. Dornyei (2001) views that exploration of the internal structure of language motivation is a debatable area. Chen (2005) views that the area of the internal structure of language motivation remained a wide area of research in the context of English as a foreign language setting.

\section{Statement of the Problem}

In the modern age of globalization, the English language has turned to become a global language. So, it is needed to explore how English can be learned as a second language. The present study aims to explore how ESL learners' can improve English comprehension skills through motivational synergy. Four skills of English language are important i.e. reading, writing, speaking, and listening. The

\footnotetext{
* Department of English Language and Literature, University of Okara, Pakistan

Email: maria.sarwar@uo.edu.pk

** Department of English/Business Management, Iqra University Karachi Email: rubinamasum@gmail.com

*** Department of Humanities, Social Sciences and Modern Languages, University of Engineering and Technology, Lahore Email: sadiagondal@uet.edu.pk
} 
present research would focus on certain skills to explore ESL learners' improvement in their comprehension skills. The study will discuss how certain motivational factors work with ESL comprehension skills in improving second language learners' comprehension skills

\section{Purpose of the Study}

Language learning is a domain not only limited to learn one's language but it explores the scope of foreign and second language learning. Pakistan is a country where English has got a great scope of learning. So, the present study focuses on how second language learners can improve their comprehension. This research also highlights what role motivation plays in language learning. Furthermore, this study helps the linguists to explore different dimensions of second language learning like the attitude of second language learners towards learning English, mastery of comprehension skills of the second language.

\section{Objectives of the Study}

- To determine the learners' motivation towards learning second language comprehension skills

- $\quad$ To improve the comprehension skills of learners learning English as a second language.

\section{Research Questions}

1. How do the comprehension skills of ESL learners be enhanced through motivational synergy?

2. What is the relationship between motivational synergy and learning English as a second language?

\section{Lite rature Review}

This section provides a theoretical framework on aspects of motivation and comprehension skills of English as a foreign language. Then, this chapter discusses the previous studies being conducted in this field of motivational synergy and second language learning. Then, different forms of comprehension skills will be discussed

\section{Motivation}

Second language learning does not occur in vacuity. Several factors are involved when there is a matter of learning a second language in general and English as a second language in particular; one such factor is motivation. Melendy in 2008 mentioned that Motivation is derived from the Latin word "movere" which means a process that a need initiates leading to such behavior which turns an individual towards achieving a certain goal (Melendy, 2008). In second language learning, points to an attempt or urge to learn a language with a positive attitude (Dornyei, 1994). The study of motivation is vital to many second language researchers because researchers that without enough drive of motivation even the most capable learners cannot attain long-term aims and set goals.

There was a revival of interest in the field of motivation and its relation with second language acquisition during the 1990s (Dornier, 1994a, 1994b, Gardner \& Tremblay 1994). Motivation is thought of to be one of the central place variables in learning of language. Gardner's (1985) social educational model suggests that motivation roots in the larger part of inter-group attitudes and have also got the attraction to target language and culture (Honda, 2005a). The relationship between motivation and attitude is of great focus in language learning research. The reason is that the motivation regarding second language learners is influenced by one's behavior regarding learning the L2.

\section{Integrative versus Instrumental Orientation}

Linguists have proposed different types of motivation but the common notions related to Gardner's work in second language learning discipline are two i.e. Integrative and instrumental motivation.Gardner\& Lambert(1959) devised the "theory of attitude and motivation" in which they differentiated between orientation and motivation. Orientation indicates the reason for learning the second language which can be integrative and instrumental. Integrative orientation is when a learner is eager to know about the culture of a language community. Integrative focuses on the integration of oneself into the speech community. If a person learns English to identify himself with that community is an integrative orientation. The aim of language learning is more practical like getting ahead in professional life, the motivation is considered to be more instrumental. Instrumental orientation focuses on the utilitarian value of developing linguistic proficiency and practical achievements of goals. 


\section{Extrinsic versus Intrinsic Motivation}

Several researchers have categorized motivation from various points of view. The cognitive viewpoint identifies two categories in motivation as extrinsic \& intrinsic motivation. Extrinsic motivation engrosses a system of punishments and rewards. This form of motivation pertains to some outer stimulus while intrinsic motivation is based on affective province/realm of emotions and feelings (Slavin, 2003). Extrinsic motivation recounts for doing an action to get a reward and to avoid punishment while intrinsic motivation recounts for doing an action or learning something for experiencing something and having self-satisfaction. An example of extrinsic motivation is that one learns English so to have a good job abroad or in England while intrinsic motivation is when somebody learns English for one's interest (Dornyei, 2001).

Globalization and English Language Learning

Wee (2003) introduces the term "Linguistic Instrumentalism "to focus that globalization and capitalism have brought changes in ideological perspectives of language groups. Giddens (1990) states globalization as the phenomenon of speeding up and strengthening worldwide connections to connect far-off places. Block \& Cameron (2002) have observed globalization as a factor influencing the changes in circumstances where learning of language takes occurs. Significant change takes place in economic circumstances. Heller (1999a) has proposed that languages (especially English) are thought of as economic commodities.

Lamb (2004) explores the integrative motivation of children in Indonesia aging between 1112 as affected by globalization and global force. These students start learning English in junior\& high school in an urban area of Malaysia. The focus notion of his work was on the idea of "integrativeness" which he believes got changed as the process of globalization prospered. This is believed by him that English gets more acquainted with the notion of globalization rather than getting associated with cultures referred to as Anglophones. The Indonesian learners of English learn this language to get attached not only to the ir own identity or culture but global identity regarding language as a result of the concept of globalization.

\section{Listening Comprehension Skills}

Listening holds an important place in our routine lives. People in daily routine listen to accomplish various goals for certain professional and academic needs. Listening skills, among four language skills, in second language acquisition has remained the least researched skill (Vandergift, 2007). Vandergift (2007) gives the reason for the difficulty in listening comprehension as insufficient and ineffective instructions and teaching methodology. The process of communication is incomplete and cannot be accomplished without ample input of listening (Cross, 1998). It is sometimes a difficult task for non-native speakers of English to develop good listening skills when they learn English as a foreign language.

\section{Listening Skill, Passive or Active}

Listening as a skill and teaching of this skill remained ignored and unattended for so many years but in today's world where second and foreign language learning and teaching is getting important, this skill is being paid attention to be taught and practiced in classroom settings. Nunan (1998) says that listening takes in a process of forming meanings out of vocal and non-vocal messages (body language and signs). Listening is thought of to be a passive communication skill as the language learner/listener sits silently lending ear to recorded or presented dialogues and writes to answer the questions of the verbal message but this process of listening demands message to be interpreted through certain coding signals in mind. The listener/learner tries to identify sounds. Then, he links words to form sentences of language to form meaning. The sentences develop an intricate text. Apart from the grammatical connections as developed by the listener, the suprasegmentally features of the language like intonation, stress, and rhythm take part in this data-driven process of listening (Van Duzer,1997). It is now clear that listening is not a passive skill as it is considered to be but it claims certain intricate processes on part of the listener. Owing to this complexity are two cognitive incorporated processes as Nunan (1998) refers first one as bottom-up cognitive processing which includes forming meaning from the smallest fraction of the verbal language to the larger ones. It is a linear process. Top-Down processing involves interpretation of the speaker's intended meaning with the help of prior or background knowledge and patterns of knowledge in the listener's/learner's mind. This point focuses on the effectiveness of schemata or already existing knowledge of the language as hold by the language learners to interpret the meaning of the message or information to which they lend their ears. 
Rost (2002) believes that comprehension of listening is a process of deducing meanings. Byrnes in 1984 indicated listening as an intricate and difficult problem-solving task and method.

\section{Process of Listening Comprehension}

In theoretical practice, listening comprehension is considered to be an active skill of a passage where the listeners/learners focus on certain parts of acoustic input, and the meaning of a passage is formed by relating existing knowledge to what they listen to. In cognitive psychology, comprehension is referred to as a method of processing information. The structures which help in comprehension are schemata. According to Rumelhart (1980, p. 34), the schema is an information retrieval that indicates the generic concepts which are put away in our memory. This schema also shows knowledge of underlying ideas, a chain of events, and experiences on part of the listener. Bottom-up Processing

This form of processing is initiated by new input. The features of data move into the system through bottom-up schemata. Schemata are formed in a hierarchical order, from the particular at the bottom and general at the top. The processing of listening starts from interpreting the smallest meaningful units to the whole text. The smallest units, phonemes, are comprehended. These phonemic units combine to form words, groups of words form phrases and phrases combine to form utterances and utterances lead towards an overall comprehension of the text. The input, in form of sounds, leads towards triggering the hierarchical structures of schemata which get organized in the mind of the listener in form of the knowledge of phonology, morphology, lexical and syntactical knowledge(Rubin,1994.p.10). Linguistic knowledge is important in bottom-up processing. Textual understanding is a process of interaction between the listener's existing knowledge and the text but linguistic knowledge is not sufficient for connecting the listener's brain with the material of the text.

\section{Top-down Processing}

This form of processing focuses on the background knowledge to comprehend and interpret the message. As Carrell \& Eisterhold (1983) state that the system forms prediction based on a generic and higher level of schemata and then, input is searched to put the received information into high level and practically satisfying schemata. In this form of listening processing, the listener uses prior contextual know ledge and situational knowledge to comprehend what one has listened to. Situation and context include first-hand knowledge of the topic, the speaker, and his relation to the particular event of listening as well as with the particular events of listening as well as with each other and with prior events. If the information received as input is not familiar to the listener, he cannot work out his schemata; the listener then relies upon his linguistic knowledge for his listening comprehension. If the listener triggers the schema and does not receive the schema he expects from the speaker, then this top-down processing results in failure (p.557). Interactive processing covers the drawbacks of bottomup and top-down processing and enhances the comprehension skills for interpreting the message.

\section{Proble ms in Mas tering Listening Comprehension Skills}

There are seven possible obstacles in mastering English language listening comprehension skills as Underwood (1989) suggests.

1) The listener cannot comprehend the message when the speaker is too speedy in his/her utterances.

2) The comprehension of the message creates trouble when there is no repetition of words and recordings in a classroom setting as the teacher sometimes cannot understand if the listener has understood the part of the text heard or he missed.

3) Listeners sometimes have a limited storage of words and their vocabulary is small. So, they cannot understand the meaning of unfamiliar words.

4) Listeners sometimes fail to identify discourse markers especially less proficient language learners. As a result, the message is not correctly interpreted.

5) Sometimes listeners do not have ample contextual knowledge. So, listeners cannot correctly interpret the whole message as mutual knowledge and common context makes communication easier. Non-verbal cues are also misinterpreted if the communicators are from different cultures.

6) If the listener is not interested in the topic, he may lose his concentration and attention. As a result, the message is not correctly interpreted.

7) The learners may sometimes in a habit of understanding every word but not understanding the meaning of a word in context. If they miss a single word, they get worried so they are discouraged by their fear of learning 


\section{Reading Compre hension Process}

There are two main processes of doing reading. The bottom-up approach involves the processes where the reader initiates the comprehension process by working on smaller units of the text. The readers concentrate on phonemic units, words and letters, syllables and phrases, and finally on sentences and division of the text in paragraphs. The written words are focused to initiate the process of forming the meanings. The top-down approach works in opposition to the bottom-up where readers use their previous knowledge by concentrating on the whole text and important information is interpreted. The readers use contextual know ledge to work with the meanings of unknown words. In his approach, reading comprehension includes the written passage, the reader to interpret the meaning and the context. The meanings are interpreted by using different approaches like the use of prior knowledge, word analysis, deducing the meanings of the text, and recognition of the important information and vocabulary. Murtagh (1989) emphasizes that incorporating both bottom-up and top-down approaches efficiently produces good readers of the second language.

\section{Role of Schema in Reading Comprehension}

When a text is written, it sometimes happens that there exists an information gap and those gaps are covered by the readers with the shared assumption of both, encoder (the writer) and the decoder (the reader). These shared assumptions lead towards effective reading comprehension and are defined as schemata. Schemata are the intellectual and mental representation of one's experiences and have got an influence on effective reading. Readers arrange the knowledge of experiences in different ways. This experiential knowledge is referred to as prior knowledge which is made up of two important factors. The first component is our practical experiences of life which we have practiced and the other is incorporated verbal experiences and the things with which we come across in our lives (Swales, 1990). The interconnected structures corresponding to the knowledge of readers regarding everyday events are considered to be the schemata (Brown,2001; Harmer,2001; Nasaji,2002). Schemata are dynamic structures as they keep on changing with experiences showing the cognitive growth of a reader. Nuttall is of the view that growth and change in schema indicate that we can learn.

Constructivis $m$ is based on constructing schema through the readers' social and psychological experiences. Readers are connected to similar texts in different aspects. The readers discuss the text in groups and literary circles to share the different aspects of written text (Calfee \& Patrick, 1995). The meanings connected to readers' socio-cultural backgrounds are interpreted from the text as explained by sociocultural theory (Vygotsky, 1978). Reading is a socially practiced activity. So, reading different texts which incorporate cultural knowledge helps to develop social and cultural understanding.

\section{Research Methodology}

The research is both quantitative and qualitative in nature which measures quantitatively significant statistical results and based on these results, qualitative analysis is done.

\section{Design of the Study}

The study involves two variables i.e. Motivational synergy and English language comprehension Skills i.e. Reading and listening. This study was co-relational in nature as the researcher intended to explore the relationship between variables included in the study. The researcher aimed to explore the relationship of an independent variable i.e. Motivational synergy with the dependent variable i.e. comprehension skills. It was not feasible for the researcher to collect data from the entire population. So, the researcher gathered data from the selected sample.

\section{The population of the Study}

The population of the study comprised all the students enrolled in the Masters in English program at campuses of the University of Education, Lahore. Three of the campuses are in Lahore and other campuses are in Jauharabad, Attock, Multan, D. G. Khan, Faisalabad, and Okara. The sample of the study was selected using a convenient purposive sampling technique.

\section{Instrumentation}

A questionnaire was designed to explore the relationship between comprehension skills and motivational synergy. The questionnaire was customized on the expert's opinion and was carefully administered to collect data. The researcher directly accessed the respondents and distributed 200 questionnaires and 150 were returned out of which only 100 were usable for data collection. The questionnaire comprised 30 items. 


\section{Motivational Synergy}

The questionnaire comprised of 10 items focusing on the independent variable, motivational synergy. These 10 items focused on different dimensions of motivational synergy i.e. Learning English is important to become an active member of society, I can get more knowledge about the world by learning English. The questionnaire comprised of 20 items of comprehension skills.10 items were related to reading skills and 10 items were related to listening skills. These comprehension skills are a dependent variable in the study.

\section{Data Analysis}

Data were analyzed based on quantitative results of the questionnaire and then, the qualitative framework was used for in-depth study. The statistical data were analyzed by applying Pearson correlation and determining the value of Cronbach's alpha. The interpretation was done by using tables and graph charts.

\section{Findings}

\section{Percentage of Motivational Synergy Responses}

To measure Motivational Synergy ten items scale was used. The items of the scale were responded by using a 5-points Likert scale where 1 (strongly disagree) to 5 (strongly agree). The Responses percentage of 100 respondents concerning the 5-points Likert scale are displayed in table 3 which is given below.

\section{Table 3}

\section{Motivational Synergy Responses Percentage}

\begin{tabular}{|c|c|c|c|c|c|c|}
\hline $\begin{array}{l}\text { Sr. } \\
\text { No }\end{array}$ & Questions & S.D & D.A & $\mathbf{N}$ & $\bar{A}$ & S.A \\
\hline 1 & $\begin{array}{l}\text { I can get more knowledge about the world by } \\
\text { learning English }\end{array}$ & $28.0 \%$ & $31.0 \%$ & $12.0 \%$ & $23.0 \%$ & $6.0 \%$ \\
\hline 2 & English is essential for getting a good job & $25.0 \%$ & $29.0 \%$ & $7.0 \%$ & $19.0 \%$ & $20.0 \%$ \\
\hline 3 & $\begin{array}{l}\text { I want to be a good communicator of the English } \\
\text { language }\end{array}$ & $23.0 \%$ & $42.0 \%$ & $4.0 \%$ & $19.0 \%$ & $12.0 \%$ \\
\hline 4 & $\begin{array}{l}\text { Learning English is important to become an } \\
\text { active member of society }\end{array}$ & $29.0 \%$ & $21.0 \%$ & $20.0 \%$ & $18.0 \%$ & $12.0 \%$ \\
\hline 5 & English is essential to learn if I travel abroad & $26.0 \%$ & $26.0 \%$ & $16.0 \%$ & $23.0 \%$ & $9.0 \%$ \\
\hline 6 & $\begin{array}{l}\text { English will help me to attain higher degrees in } \\
\text { future }\end{array}$ & $13.0 \%$ & $21.0 \%$ & $8.0 \%$ & $24.0 \%$ & $34.0 \%$ \\
\hline 7 & English class is my favorite class & $19.0 \%$ & $13.0 \%$ & $9.0 \%$ & $27.0 \%$ & $32.0 \%$ \\
\hline 8 & $\begin{array}{l}\text { I feel good when I use English to become a part } \\
\text { of classroom discussions }\end{array}$ & $13.0 \%$ & $10.0 \%$ & $9.0 \%$ & $27.0 \%$ & $41.0 \%$ \\
\hline 9 & $\begin{array}{l}\text { I use English in everyday discussions and } \\
\text { conversation }\end{array}$ & $11.0 \%$ & $10.0 \%$ & $17.0 \%$ & $19.0 \%$ & $43.0 \%$ \\
\hline 10 & $\begin{array}{l}\text { I learn English because it is an international } \\
\text { language }\end{array}$ & $12.0 \%$ & $12.0 \%$ & $9.0 \%$ & $27.0 \%$ & $40.0 \%$ \\
\hline
\end{tabular}

\section{Bar Chart of Motivational Syne rgy Responses}

Q1 indicates that the frequency of respondents in disagree bar is high as compared to other bars and the frequency of respondents in the strongly agree bar is depressed as compared to other bars. A psychological bar chart indicates that prominent respondents disagree and strongly disagree with the panorama, I can get more knowledge about the world by learning English and minority respondents strongly agree with that panorama. The bar chart also suggesting that some respondents are neutral. Q2 indicates that the frequency of respondents in disagree bar is high as compared to other bars and the frequency of respondents in the Neutral bar is depressed as compared to other bars. Psychologically bar chart indicates that prominent respondents disagree and strongly disagree with the panorama, English is essential for getting a good job and minority respondents are neutral. The bar chart also suggesting that some respondents are. Agree and strongly agree with that panorama.

Q3 indicates that the frequency of respondents in disagree bar is high as compared to other bars and the frequency of respondents in the Neutral bar is depressed as compared to other bars. A psychological bar chart indicates that prominent respondents disagree and strongly disagree with the panorama, I want to be a good communicator of the English language and minority respondents are neutral. A bar chart is also suggesting that some respondents agree and strongly agree with that panorama. A minority remains neutral on their view of becoming a good communicator of English. 
Q4 indicates that the frequency of respondents in the strongly disagree bar is high as compared to other bars and the frequency of respondents in the strongly agree bar is depressed as compared to other bars. Psychologically, the bar chart indicates that prominent respondents strongly disagree and agree with the view of learning English to become an active member of society but a minority of the respondents strongly agree with this view. Bar Chart is also suggesting that the majority of the respondents strongly disagree and agree with the priority of learning English for becoming an active member of the society but the minority strongly agrees with the phenomenon that one becomes an active member of the society if he learns English.

Q5 indicates that the frequency of respondents in the strongly disagree bar is high and the frequency of respondents in the strongly agree bar is depressed as compared to other bars. Psychologically, the bar chart indicates that prominent respondents strongly disagree, agree, and remained neutral on the view of the importance of English for traveling abroad but a minority of the respondents strongly agree with this view of the importance of English. The chart is also suggesting that the majority of the respondents strongly disagree and remained neutral on the priority of learning English to travel abroad but the minority has shown interest in learning English if one wants to travel abroad.

Q6 indicates that the frequency of respondents in the strongly disagree bar is high and the frequency of respondents in the neutral bar is depressed as compared to other bars. Psychologically, the bar chart indicates that prominent respondents strongly disagree, disagree, and agree on the view of the importance of English for attaining higher degrees but a minority of the respondents remained neutral on this view of the importance of English. The chart is also suggesting that the majority of the respondents strongly disagree and agree on the priority of learning English to get higher degrees in the future but a minority have remained neutral on the view of learning for attaining a higher degree in the future.

Q7 indicates that the frequency of respondents in the strongly agree bar is high as compared to other bars and the frequency of respondents in the Neutral bar is depressed as compared to other bars. A psychological bar chart indicates that prominent respondents strongly agree and strongly disagree with the view that English class is my favorite class and minority respondents are neutral. A bar chart is also suggesting that some respondents strongly agree and strongly disagree with the perspective of liking one's English. A minority of the respondents are neutral on their view of having English class as their favorite one.

Q8 indicates that the frequency of respondents in the strongly agree bar is high as compared to other bars and the frequency of respondents in the Neutral bar is depressed as compared to other bars. A psychological bar chart indicates that prominent respondents agree and strongly agree from the feeling of goodness on becoming part of classroom discussions by using English and minority respondents are neutral. A bar chart is also suggesting that some respondents strongly disagree and disagree with the perspective of feeling good to use English for becoming a part of classroom discussions.

Q9 indicates that the frequency of respondents in the strongly agree bar is high as compared to other bars and the frequency of respondents in disagree bar is depressed as compared to other bars. A psychological bar chart indicates that prominent respondents strongly agree and agree to the usage of English in everyday discussions and conversations. Minority respondents disagree with the perspective of using English in everyday discussions and conversations. A bar chart is also suggesting that some respondents agree and are neutral with that panorama. Minority disagrees with the view of using English in everyday discussions and conversations.

Q10 indicates that the frequency of respondents in the strongly agree bar is high as compared to other bars and the frequency of respondents in the Neutral bar is depressed as compared to other bars. Psychologically bar chart indicates that prominent respondents strongly agree and agree with the panorama of learning English as it is an international language. A bar chart is also suggesting that some respondents strongly disagree and disagree with the perspective of using English as an international language. A minority of the respondents are neutral on the ir view of using English as an international language.

\section{Percentage of Learne r's Compre hension Skills Response}

To measure Learner's Comprehension Skills twenty items scale was used. The items of the scale were responded by using a 5-points Likert scale where 1 (strongly disagree) to 5 (strongly agree). The Responses percentage of 100 respondents concerning the 5-points Likert scale are displayed in table 4 which is given below. 


\section{Table 4}

Le arne r's Comprehension Skills Responses Percentage

\begin{tabular}{|c|c|c|c|c|c|c|}
\hline $\begin{array}{l}\text { Sr. } \\
\text { No. }\end{array}$ & Questions & S.D & D.A & $\mathbf{N}$ & $\mathbf{A}$ & S.A \\
\hline & READING & & & & & \\
\hline 1 & I spend ample time reading & $22.0 \%$ & $54.0 \%$ & $1.0 \%$ & $12.0 \%$ & $11.0 \%$ \\
\hline 2 & My course books help me to become a good reader & $35.0 \%$ & $40.0 \%$ & $6.0 \%$ & $8.0 \%$ & $11.0 \%$ \\
\hline 3 & I read my textbooks daily in my leisure time & $34.0 \%$ & $40.0 \%$ & $2.0 \%$ & $14.0 \%$ & $10.0 \%$ \\
\hline 4 & $\begin{array}{l}\text { I use illustrations to interpret the meanings of the } \\
\text { text }\end{array}$ & $30.0 \%$ & $47.0 \%$ & $0.0 \%$ & $16.0 \%$ & $7.0 \%$ \\
\hline 5 & I try to guess the meanings of words in context & $35.0 \%$ & $51.0 \%$ & $6.0 \%$ & $5.0 \%$ & $3.0 \%$ \\
\hline 6 & $\begin{array}{l}\text { When I don't understand a word, I use the already } \\
\text { read information to guess its meanings. }\end{array}$ & $61.0 \%$ & $19.0 \%$ & $12.0 \%$ & $2.0 \%$ & $6.0 \%$ \\
\hline 7 & $\begin{array}{l}\text { When I find a text difficult, I use different } \\
\text { strategies to understand its meanings }\end{array}$ & $1.0 \%$ & $1.0 \%$ & $14.0 \%$ & $25.0 \%$ & $59.0 \%$ \\
\hline 8 & When I read, I visualize the text in my mind & $1.0 \%$ & $4.0 \%$ & $10.0 \%$ & $25.0 \%$ & $60.0 \%$ \\
\hline 9 & $\begin{array}{l}\text { I use a dictionary to find out meanings of difficult } \\
\text { words }\end{array}$ & $4.0 \%$ & $3.0 \%$ & $12.0 \%$ & $25.0 \%$ & $56.0 \%$ \\
\hline 10 & I like to be tested for reading comprehension test & $1.0 \%$ & $0.0 \%$ & $12.0 \%$ & $25.0 \%$ & $62.0 \%$ \\
\hline 11 & $\begin{array}{l}\text { I think about failing when I take a reading } \\
\text { comprehension test } \\
\text { LISTENING }\end{array}$ & $1.0 \%$ & $1.0 \%$ & $12.0 \%$ & $21.0 \%$ & $65.0 \%$ \\
\hline 12 & I feel that I am a good listener & $2.0 \%$ & $2.0 \%$ & $14.0 \%$ & $41.0 \%$ & $41.0 \%$ \\
\hline 13 & I feel distractible when I listen to someone & $3.0 \%$ & $2.0 \%$ & $10.0 \%$ & $27.0 \%$ & $58.0 \%$ \\
\hline 14 & $\begin{array}{l}\text { I sometimes feel difficulty with sound } \\
\text { discrimination }\end{array}$ & $2.0 \%$ & $4.0 \%$ & $17.0 \%$ & $14.0 \%$ & $63.0 \%$ \\
\hline 15 & $\begin{array}{l}\text { I get confused to listen to someone with any } \\
\text { background noise }\end{array}$ & $1.0 \%$ & $3.0 \%$ & $29.0 \%$ & $29.0 \%$ & $59.0 \%$ \\
\hline 16 & I try not to talk to anyone when the teacher speaks & $4.0 \%$ & $8.0 \%$ & $6.0 \%$ & $50.0 \%$ & $32.0 \%$ \\
\hline 17 & I listen even if I disagree with the speaker's ideas & $1.0 \%$ & $3.0 \%$ & $12.0 \%$ & $47.0 \%$ & $37.0 \%$ \\
\hline 18 & $\begin{array}{l}\text { When I listen to someone, I try to separate the } \\
\text { verbal and non-verbal clues }\end{array}$ & $2.0 \%$ & $4.0 \%$ & $12.0 \%$ & $47.0 \%$ & $35.0 \%$ \\
\hline 19 & $\begin{array}{l}\text { As a listener, I try to have an eye-contact with the } \\
\text { speaker }\end{array}$ & $3.0 \%$ & $19.0 \%$ & $0.0 \%$ & $41.0 \%$ & $37.0 \%$ \\
\hline 20 & I can recall what I listen in my long-term memory & $3.0 \%$ & $3.0 \%$ & $23.0 \%$ & $41.0 \%$ & $30.0 \%$ \\
\hline
\end{tabular}

\section{Corre lation analysis}

Correlation analysis is used to find out the relationship between two variables. Authors have used a person's correlation coefficient to quantify the linear relationship between motivational synergy and learners' comprehension skills. The output of correlation analys is with mean and standard deviation is displayed in table 3 given below.

Table 3

Mean, Standard De viation, and Corre lation

\begin{tabular}{ccllll}
\hline \multicolumn{2}{l}{ Variables } & Mean & S.D & 1 & 2 \\
\hline 1. & Motivational Synergy & 3.12 & .71 & 1 & \\
2. Learner's $\quad$ Comprehension & 3.58 & .44 & $.422^{* *}$ & 1
\end{tabular}
Skills

$\mathrm{N}=100,{ }^{*} \mathrm{p}<0.05$, and $* * \mathrm{p}<0.01 ; * * * \mathrm{p}<0.001$, Corre lation is significant at the 0.01 level (2-tailed). The output of the analysis shows the correlation coefficient for two variables. The result displayed that each variable is perfectly correlated with itse lf because the value of the correlation coefficient is one $(\mathrm{r}=1)$ that shows that each variable is perfectly correlated with itself. The output also displayed Learners Comprehension Skills are positively related to Motivational Synergy with a person's correlation coefficient of $r=0.422$ which is significant at $p<0.01$. Psychologically this all means that as motivational synergy increases, the learner's comprehension skills are also increase. The result also suggested that hypothesis H1: ESL learner's comprehension skills can be improved through motivational synergy was accepted because the p-value is less than $0.05 \%$ level of significance.

\section{Conclusion}

The main objective of the study was to explore the relationship between comprehension skills and the Motivational synergy of ESL learners. Findings of the study reveal that comprehension skills possess a significant positive correlation with the motivational synergy of ESL learners. The findings of the 
study are significantly consistent with the studies of Dornyei (1990), Gardner and Macintyre (1991), Clement and Dornyei (1994) which concluded that motivation is significantly correlated to second language learning. The findings reveal that listening comprehension of ESL learners significantly positively correlated to motivational synergy. These findings are significantly consistent with the results of Jafari. M who in his study of Iranian EFL learners' concluded that students with higher motivation spent more time, created more opportunities, and paid more attention to developing and enhancing their English listening comprehension. The results of the present study are also significantly consistent with the findings of Hsu (2006). In his study of Taiwanese EFL College Learners' and the effect of motivation on listening comprehension, Hsu concluded that students with high motivation build more self-confidence and create opportunities to enhance their listening skills. They are capable of understanding the content of listening comprehension and score high in listening comprehension tests. The findings of positive correlation between listening comprehension and motivational synergy are significantly consistent with results of the study carried out by Zhang (2000) which indicated that listening should involve a variety of techniques to motivate students and keep their interest high in the contents. In this way, students can make good progress in listening comprehension. The present study revealed that there is a significant positive correlation between reading comprehension and motivational synergy. The results are significantly consistent with the results of Taboada. An as her study revealed that motivation \& background knowledge significantly contributes to children's reading comprehension. When a learner learns a second language, his comprehension is enhanced through motivation. This improvement in comprehension through motivation leads to better learning of a language. Furthermore, comprehension skills lead to understanding and interpretation of meanings in a language. Learning a second language becomes easier if the comprehension skills are mastered and this mastery is significant if a learner is motivated to learn. The students with stronger reading motivation can be expected to read more in a wider range. Following are the findings of the study;

- Motivation is an important factor to learn English as a second language.

- English comprehension as a second language can be improved if learners' motivation correlates to their comprehension skills.

- $\quad$ Reading and listening are important skills of comprehension.

- $\quad$ Listening skills are enhanced by significantly enhancing learners' motivational synergy.

- $\quad$ Reading comprehension is significantly correlated with motivational synergy.

- $\quad$ ESL learners focus on their background knowledge to interpret meanings in the context.

- $\quad$ English as considered to be a global and prestigious language motivates second language

References learners to enhance their comprehension.

Byrnes, H. (1984). The Role of Listening Comprehension: A Theoretical Base. Foreign Language Annals; New York.Vol.17, Iss.4

Block. D \&Cameron, B. (2002). Globalization and Language Teaching. London and New York: Routledge research theory, and classroom practice. San Francisco. Ca: Jossey-Bass

Brown, H.D. (2001). Teaching by Principles. An Interactional Approach to Language Pedagogy. White Plains. NY

Carrell, P.L., \& Eisterhold, J.C. (1983). Schema theory and ESL Reading Pedagogy.TESOL Quarterly, 17(4).553-573

Calfee, R.C. \& Patrick, C.L. (1995). Teach Our Children Well. Stanford, CA: Stanford Alumni Association.

Cummins, J. (2000). Language, Power, and Pedagogy. Bilingual Children in the Crossfire. Cleveland England: Multilingual Matters.

Chen, J.F., Warden, C.A., \&Chang, H.T., (2005). Motivators that do not motivate. The case of Chinese EFL Learners and the influence of culture on motivation. TESOL Quarterly, 39(4).609-633.

Dornyei, Z. (1990). Analys is of Motivation Components in Foreign Language Learning. Paper presented at World Congress of Linguistics

Dornyei, Z. (1994 a). Motivation and motivation in the foreign language classroom. Modern Language Journal, 78,273-284.

Dornyei, Z. (1994 b). Understanding L2 motivation: On with the challenge. Modern Language Journal, 78,513-523. 
Dornyei, Z. (2001). Motivational Strategies in the Language Classroom. Cambridge: Cambridge University Press. http://dx.doi.org/10.1017/CBO980511667434

Duke, N, K. \& Carlisle, J. (2011). The development of comprehension. In M.L. Kamil., P.D. Pearson. E. Birr, Moje \& Afterbach. Handbook of Reading Research. Vol II (pp.99-112). Nayak.Routledge.

Gardner, R.C., \&Lambert, W.E. (1959). Motivational variables in second-language acquisition. Canadian Journal of psychology/Revue Canadienne de Psychologie, 13(4), 266.

Gardner, R.C. (1985). Social psychology and second language learning: The role of attitudes and motivation. Arnold.

Gardner, R.C. \&Lambert, W.E. (1972). Attitudes and Motivation in Second -Language Learning. Rowley, MA: Newbury House.

Gardner, R.C. \&Macintyre, P.D. (1993). A student's contributions to second-language learning. Part II: Affective variables. Language teaching, 26(01), 1-11.

Gardner, R.C. \&Tremblay, P.F. (1994). On Motivation, Research agendas, and Theoretical Frameworks. The Modern Language Journal, 78(3), 359-368.

Giddens, A. (1990). The Consequence of Modernity. Cambridge: Polity Press

Heller, M. (1999). Linguistic Minorities and Modernity. A Sociolinguistic Ethnography. London: Longman

Harmer, J. (2001). The Practice of English Language teaching (3rd Ed). Harlow: Longman

Honda, K., \&Sakyu, M. (2005). The concurrent and construct of intrinsic/extrinsic motivation in Japanese EFL learners: A self-determination theory practice.

Hsu, Y-Y. (2006) Extensive Reading and EFL Junior College Students in Taiwan (Unpublished Paper).

Lamb, M. (2004). Integrative motivation in a globalizing world. The system, 32(1). pp 319.https//doi.org/10.1016/j.system.2003.04.002

Murtagh, L. (1989). Reading in a Second Language. Models, Processes and Pedagogy. Language, Culture and Curriculum, 2(2), 91https://doi.org/10.1080/07908318909525058

Melendy, G. (2008). Motivating writers: The power of choice. The Asian EFL Journal, 10(3), 187 198,retrievedfromhttp://www.asianefljournal.com/September_08_gm.php

Nunan, D. (1998). Approaches to teaching listening in the language classroom Paper presented at the Korea TESOL Conference, Seoul

Nassaji, H. (2003). Higher level and Lower level Text Processing Skills in Advanced ESL Reading Comprehension. The Modern Language Journal, 87,261-276

Pourhesein Gilakjani, A. (2012). A study of factors affecting EFL Learner's English and the strategies for instruction. International Journal of Humanities and Social Science, 2.3, 119-128.

Rumelhart, D. (1980). Schema: The Basic building blocks of Cognition. In R. Spiro, B. Brice. Brewer. (Eds), Theoretical issues in reading comprehension, Hillsdale, NJ: Erlbaum

Rubin, J. (1994). A Review of Second Language Listening Comprehension Research. The Modern Language Journal Vol7 No. 2.199-221.https://doi.org/10.2307/329010

Rost, M. (2002). Teaching and Researching Listening. London, UK: Longman

Swales, J.M. (1990). Genre Analysis, Cambridge: Cambridge University Press

Slavin, R. E. (2003): Educational Psychology. Boston: Allyn and Bacon. Students as to achievement, gender, and age. Inquiry, 9(1). Students' journal of educational psychology, 80(2), 210-216

Tapinta, P. (2006). Exploring Thai EFL University's student's awareness of their knowledge, use, and control of strategies in reading and writing. Ph.D. Thesis. University of North Texas

Underw ood, M. (1989). Teaching Listening. London: Longman

Vytgosky, L.S. (1978). Mind in Society. The Development of Higher Psychology.

Van Duzer, C. (1997). Improving ESL learners' listening skills: at the workplace and Beyond. Washington $D C$ : National Clearinghouse of ESL Literacy Education.

Vander gift, L. (2006). Second language listening: Listening ability or language proficiency? The Modern Language Journal, 90, 6-18

Vander gift, L. (2007). Recent developments in second and foreign language listening comprehension research. Language Teaching, 40,191 201.doi10.1017/S0261444807004338

Wee, L. (2003). Linguistic instrumentalism in Singapore. Journal of Multilingual and Multicultural Development, 24, 211-224 doi: 10.1080/0143460308666499

Zhang, Y.J. (2000). Warm-Up exercises in listening classes. The Internet TESL Journal, Vol.6. 